\title{
High tone lowering and raising in Tsua
}

\author{
Timothy K. Mathes \\ Department of Linguistics, New York University, USA \\ E-mail: tkm237@nyu.edu
}

Andy Monthusi Chebanne

Faculty of Humanities, University of Botswana, Botswana

E-mail: chebanne@ub.ac.bw

\begin{abstract}
The Tsua language is an Eastern Kalahari Khoe language of Botswana (Chebanne 2014). Tsua tone production displays complex Fundamental Frequency (F0) trajectories. Lexical data show that this language has three tone levels: High $(\mathrm{H})$, Mid $(\mathrm{M})$, and Low $(\mathrm{L})$, with the following surface tone melodies: [HH, HM, HL, MM, MH, ML]. High tones may be lowered when they occur following voiced obstruents, aspirated obstruents or the glottal fricative $/ \mathrm{h} /$ in root-initial position, a typologically rare pattern. This results in two depressed melodies: depressed HM [DH-M] and depressed HL [DH-L]. Both clicks and non-clicks participate in this interaction. We refer to this tonal depression pattern as High Tone Lowering (HTL). HTL may be formally accounted for via the Low tone insertion rule: $\varnothing \rightarrow \mathrm{L} /$ [-sonorant, +slack] $\mathrm{H}[-\mathrm{H}] \#$. Recent analysis suggests that Super High $(\mathrm{SH})$ tones are derived from $/ \mathrm{H} /$ when docked to the high vowels [i], [u] and are not phonemic. For example, underlying /HL/ tüu "to collect and remove ash" is produced with SH-L tones on the surface. We refer to this as High Tone Raising (HTR). Elderkin (1988) reports a similar finding in Ju|'hoan in which a sequence of successive extrahigh tones is only found in click-initial morphs when the final vowel is [i] or [u]. It may be that an Intrinsic F0 (IF0) effect from the Tsua high vowels was a historical factor that led to the genesis of HTR. Given that voiced, aspirated and /h/ consonant types depress a root-initial $\mathrm{H}$ tone and the high vowels [i], [u] raise $\mathrm{H}$ tones, the paper considers phonetically-driven origins of these patterns.
\end{abstract}

Keywords: tone; depressor consonants; high vowels; Khoisan; Intrinsic F0

\section{Introduction}

Tone production varies considerably in terms of how complex Fundamental Frequency (F0) trajectories may be cross-linguistically. A complex F0 trajectory is defined here as excursions between the F0 onset, F0 maximum, F0 minimum and F0 offset that are not flat and may even 
be extreme over the course of a tone or tone melody. Original field research reveals that the Khoisan language Tsua's tone melodies have complex F0 trajectories.

Tsua is classified by Güldemann (2006) and Güldemann and Vossen (2000) as a Kalahari Khoe East language and part of the Tshwa subgroup. The Tsua tonal melodies with F0 shapes having the most extreme excursions are the result of a rare consonant-tone interaction pattern with depressor types found in both African and East Asian tone languages. The Tsua depressor types are voiced obstruents, aspirated obstruents and the glottal fricative $/ \mathrm{h} /$. The depressor target is a root-initial High $(\mathrm{H})$ tone. Both click and non-click consonants participate in the interaction. The pattern's rarity can be observed when we consider cross-linguistic data on depressor consonants in Bradshaw (1999) and Tang (2008). It is quite common for voiced obstruents to be tone depressors, particularly in African languages. Aspirated obstruents are reported to be depressors in many East Asian languages. It is not common for the glottal fricative $/ \mathrm{h} / \mathrm{to}$ be a depressor in either African or East Asian languages. It is rare for all three depressor types to be found in one language as in Tsua. This depression pattern, in which a root-initial High tone is lowered in terms of F0, is referred to here as High Tone Lowering (HTL).

Recent analysis suggests that High tones are raised to Super High (SH) when linked to high vowels [i, u]. We refer to this phenomenon as High Tone Raising (HTR). Elderkin (1988) reports a similar finding in Ju|'hoan, in which a sequence of successive extra-high tones is only found in click-initial morphs when the final vowel is [i] or [u]. $\mathrm{H}$ tones are particularly important in the Tsua tonal system, being the target of two phonological processes. Thus, the central aim of this paper is to describe Tsua lexical tone production and to explore the historical factors that may have led to HTL and HTR.

\section{Tsua lexical tone production}

\subsection{Basic melodies}

The phonetic realizations of Tsua's six basic tonal melodies are presented in this section. These realizations are based on field research conducted with three female Tsua speakers referred to as S, B and M. Their reported ages are 78, 57 and 80, respectively. The melodies are described in turn using a selection of F0 pitch traces and spectrograms from the Tsua data set plotted by speaker. More detailed quantification through F0 logarithmic averaging and time-normalization can be seen in Mathes (2015). The purpose is to highlight the relevant characteristics of speaker variability as well as to justify the labellings. For the interested reader, Mathes (2016) gives a detailed description of the Tsua segmental inventory while details on Khoisan morphology can be found in Güldemann and Vossen (2000) and Vossen (2013).

\subsection{High-level melody}

Figure 1 below shows spectrograms and F0 traces of the High-level noun /ám/ "sun” spoken in citation form by speakers S, B and M from left to right. The High-level melody is produced with the highest Hertz value and lowest F0 excursion, i.e. it has the flattest pitch, compared to the other 5 melodies. All three speakers produce it as phonetically falling to some extent over the course of a given bimoraic root. The slope of the fall is more pronounced for speaker B in her tokens as seen in Figure 1's middle pitch trace. The fact that the Tsua High-level melody falls a certain extent is unsurprising; in perceptual studies of Thai level tones, Abramson (1975, 
1978) found that Thai speakers were less confused and accepted synthetic speech with some pitch movement as level compared to synthetic speech with no pitch movement. Moreover, referring to acoustic studies of Yoruba tones, Laver (1994:467) states: "Acoustic analysis reveals, not surprisingly, that in real speech the pitches of the so-called 'level' tones are seldom strictly level.” This is the case for the Tsua High-level melody as well.

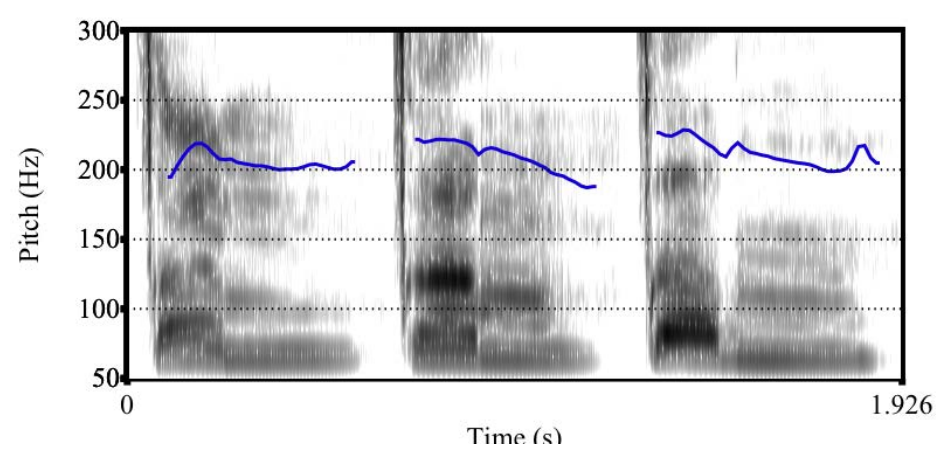

Figure 1: F0 traces with spectrograms of the High-level noun /ám/ “sun” spoken in citation form by speakers $S, B$ and $M$ displayed from left to right

\subsection{HM-falling melody}

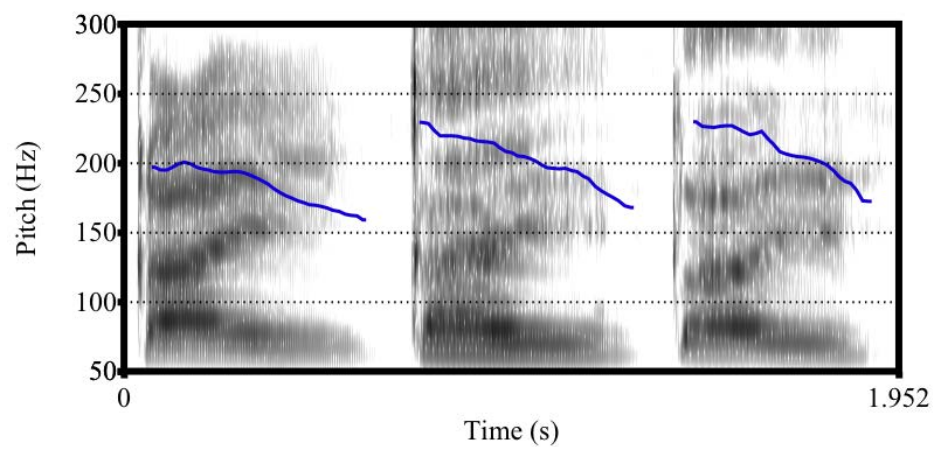

Figure 2: F0 traces with spectrograms of the HM-falling verb /láē/ "to chew" spoken in citation form by speakers $S, B$ and $M$ displayed from left to right

Figure 2 shows F0 traces and spectrograms of HM-falling melodies produced by the three Tsua consultants S, B and M. The HM-falling melody often has a short rise after the F0 onset and then falls to the F0 offset. One property that distinguishes the HM-falling melody from the High-level melody is the nature of the fall towards the end of the contour for the HM-falling melody. Moreover, the High-level melody at times has a final rise more evident in tokens produced by speakers S and $\mathrm{M}$, a rise seen when F0 averaged and time-normalized across multiple tokens not shown here (see Mathes 2015). All three consultants produce the HMfalling melody with a pitch that falls more dramatically to the F0 offset pitch compared to the High-level melody, but less so when compared to the HL-falling melody shown in the next section. 


\subsection{HL-falling melody}

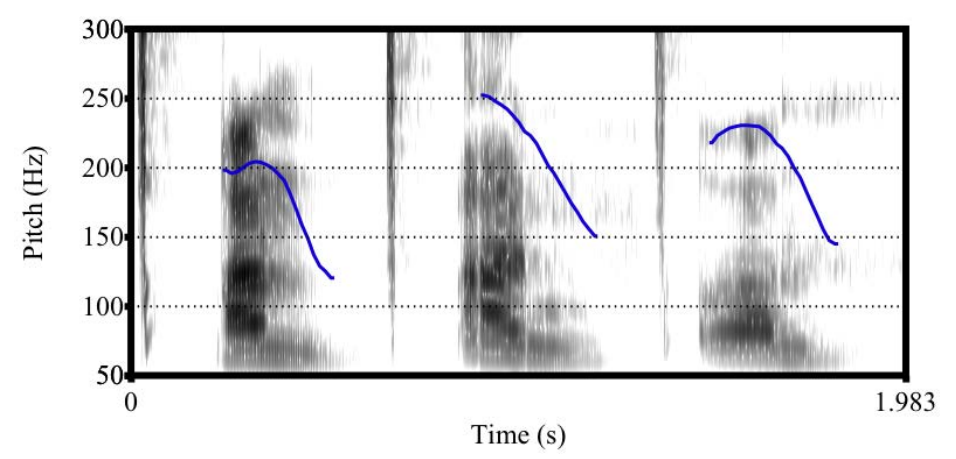

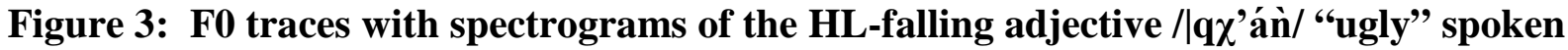
in citation form by speakers $S, B$ and $M$ displayed from left to right

Exemplars of the HL-falling melody are shown in Figure 3 for / $q \chi \chi$ 'án/ "ugly”. There is a short rise at the beginning of the contour for speakers $\mathrm{S}$ and $\mathrm{M}$ before the precipitous fall in many of their tokens. What is important to the identification of this salient melody is the range and speed of the fall. The HL-falling melody has a larger range and decreased duration with respect to the fall compared to the HM-falling melody.

\subsection{Mid-double-rise melody}

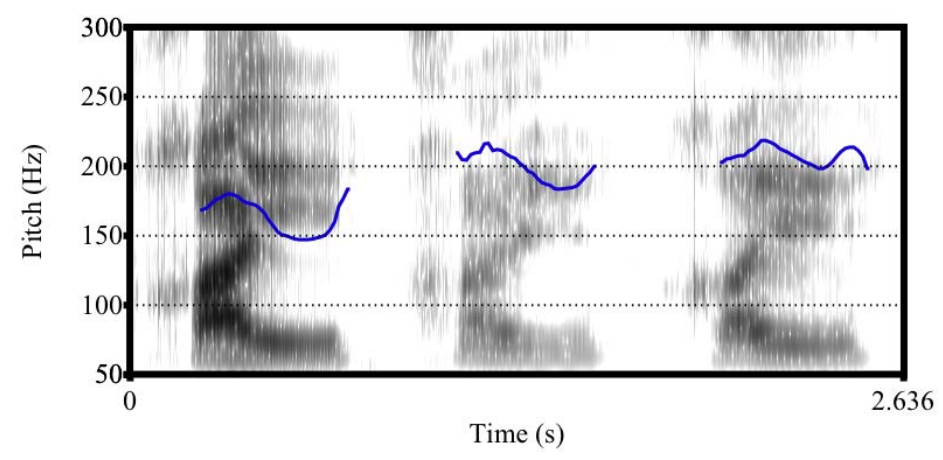

Figure 4: F0 traces with spectrograms of the Mid-double-rise noun / $\chi \bar{a} \bar{e} /$ "night" spoken in citation form by speakers $S, B$ and $M$ displayed from left to right

The Mid-double-rise melody is shown in Figure 4 by speaker for the noun / $\chi \bar{a} \bar{e} /$ "night". The Mid-double-rise melody is often characterized by a rise in pitch from the F0 onset, followed by a drop, then a rise towards the end of the melody. The result is a pitch wavering quality. It is possible that this up-and-down wavering is a phonetic effect that helps differentiate the Middouble-rise melody from the High-level melody, especially in running speech. In many of the consultants' tokens, the initial rise of the Mid-double-rise melody approaches but never quite reaches the High tone pitch levels of the melodies with High tones, i.e., High-level, HM-falling and HL-falling. The Mid-double-rise is consistently higher throughout compared to the Low 
tone in the HL-falling melody but lower than the High tones in the High-level, HM-falling and HL-falling melodies.

\subsection{MH-rising melody}

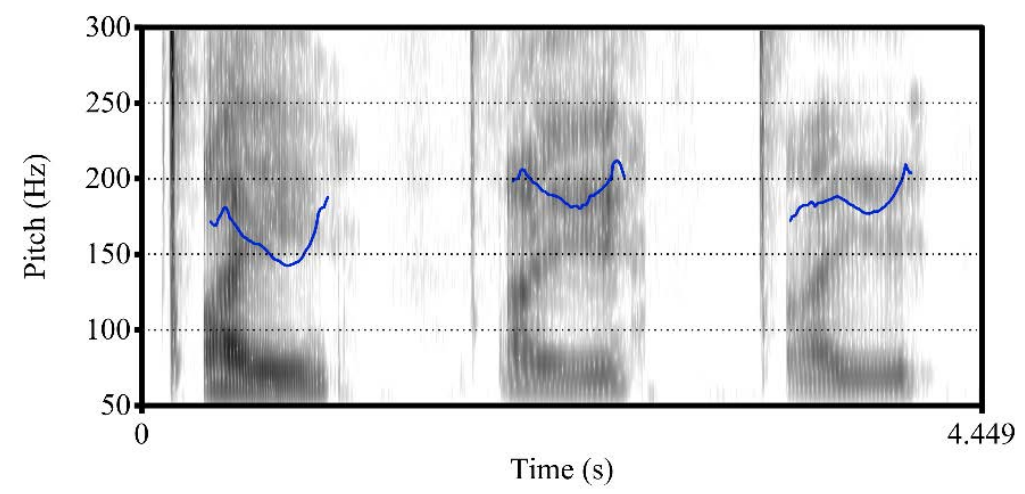

Figure 5: F0 traces with spectrograms of the MH-rising verb /|q $\chi$ 'āé/ "to fall down" spoken in citation form by speakers $S, B$ and $M$ displayed from left to right

Typical MH-rising melodies for the Tsua consultants are shown in Figure 5. The MH-rising melody falls from the F0 onset with a moderate slope until it sharply turns and increases quickly to the F0 levels comparable to the High tones in the High-level, HM-falling and HL-falling contours. Speakers S and B produce a more pronounced F0 dip before the final rise. Speaker M has less of a dip for $\mathrm{MH}$ generally, with a steady rise from $\mathrm{M}$ to the $\mathrm{H}$ tone target.

\subsection{ML-falling melody}

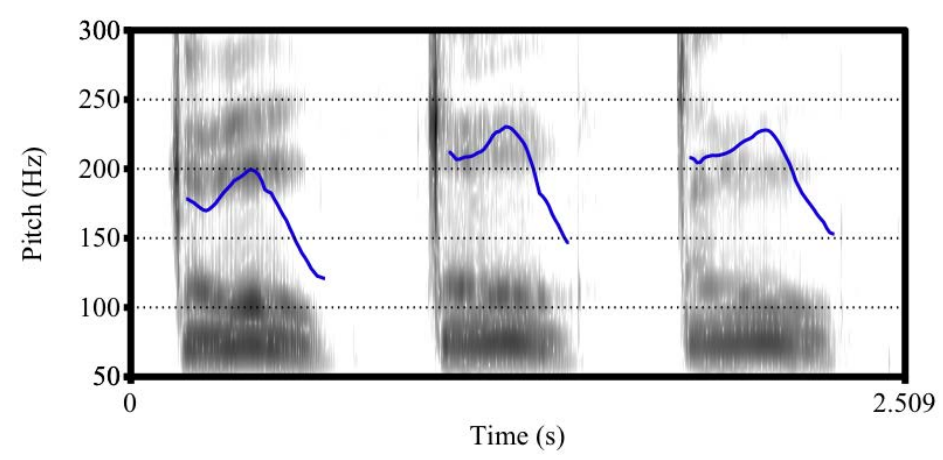

Figure 6: F0 traces with spectrograms of the ML-falling verb /|̄ò) "to run after (when hunting)” spoken in citation form by speakers S, B and M displayed from left to right

Typical ML-falling contours are displayed by consultant in Figure 6 with the verb /|ò̀/ "to run after (when hunting)". The F0 traces reveal that the ML-falling melody starts with a moderatelysloped rise from the F0 onset for the first half of the contour, followed by a quick fall to the $\mathrm{L}$ tone F0 level similar to the HL-falling melody and yet below the M tone F0 range for the HM- 
falling and Mid-double-rise melodies. The rise before falling could also be interpreted as a language-specific phonetic property.

\section{Tonological analysis and proposed representations}

The findings on other Khoisan tone systems inform the current Tsua analysis. For instance, Haacke $(1999,2008)$ posits four tone levels in Khoekhoe that are labelled using numbers 1 through 4.1 indicates the lowest tone while 4 indicates the highest. Haacke identifies six major citation melodies and their corresponding sandhi forms. Two of the sandhi forms, /21/ and /22/, each occur with two of the six main citation melodies.

Khoekhoe citation and sandhi melodies

$\begin{array}{lll}\text { Melody } & \text { Citation Form } & \text { Sand } \\ \text { Double-Low } & / 12 / & / 21 / \\ \text { Low-Rising } & / 13 / & / 13 / \\ \text { Low (level) } & / 22 / & / 22 / \\ \text { High (falling) } & / 32 / & / 21 / \\ \text { High-Rising } & / 24 / & / 22 / \\ \text { Double-High } & / 43 / & / 43 /\end{array}$

There are sixteen theoretically possible sets of tonal combinations in the four tone system in (1). Haacke addresses the six attested versus sixteen possible issue in part by arguing that there are a number of minor melodies, although he considers them exceptional since they are rare. The combination of the major and exceptional melodies accounts for twelve of the sixteen possible sets.

The tonal system of G|ui is studied in Nakagawa (2006, 2009). Nakagawa uses a three tone system of High, Mid and Low to account for six major melodies: three level and three contour melodies. These bimoraic melodies occur with CVV, CVN and CVCV syllable structures labelled as tonological Domain 1 (DOM1) and are transcribed as HH, HM, HL, MM, LM and LL. He proposes a second tonological domain, Domain 2 (DOM2), in which non-roots are limited to the /H/ vs. /L/ two-way tonal contrast. The DOM2 non-roots can be monomoraic or bimoraic, having either one or two Tone Bearing Units (TBUs), respectively. Thus, the DOM2 non-roots have a single tone associated with either one TBU or multiply linked to two TBUs.

Table 1 contains a Tsua tonal near-minimal sextuplet. The Tsua basic tone melodies can be analysed as in Table 1 based on a large number of F0 traces, comparative data from Kua (Chebanne and Collins 2014) and tonal descriptions of other languages from the Khoisan literature. The representations should account for some tokens in which the F0 targets are not attained by the consultants for the two monotonal melodies High-level and Mid-double-rise. We posit three underlying tones, High, Mid and Low, to adequately account for the observed melodies. Thus, the two-level melodies with the underlying tones $/ \mathrm{H} /$ or $/ \mathrm{M} /$, reflect the multiple association of one tone to two morae in a bimoraic root. For instance, the High-level melody is interpreted as having one $\mathrm{H}$ tone linked to the first mora while spreading to the second. The three falling melodies associate sequences of two successive tones, one tone linked to each mora in a root. What is surprising is the lack of a phonological /L/ that surfaces as a Low-level melody LL. The Tsua data set does not have instances of LM or LH either. Hagman (1977) 
reports six root melodies of the nine possible in the three tone Khoekhoe system: $\mathrm{HH}, \mathrm{HM}, \mathrm{MH}$, MM, LH and LM. LL is not attested in Hagman's analysis, although subsequent studies of Khoekhoe do posit a Low-level melody (Haacke 1999, 2008; Brugman 2009). It is unclear at this time why LL, LM and LH melodies do not occur in Tsua.

\begin{tabular}{|c|c|c|c|c|}
\hline $\begin{array}{l}\text { Lexical } \\
\text { Item }\end{array}$ & Gloss & Phonetic Label & Tone Melody & $\begin{array}{c}\text { Tonological } \\
\text { Analysis }\end{array}$ \\
\hline \|áé & “to teach” & High-level & $\mathrm{HH}$ & /H/ \\
\hline \|áē & "to chew" & HM-falling & $\mathrm{HM}$ & /HM/ \\
\hline \|áè & "to brood (eggs)" & HL-falling & HL & /HL/ \\
\hline$\| \bar{a} \bar{e}$ & "seed necklace" & Mid-double-rise & MM & $/ \mathrm{M} /$ \\
\hline$\| \bar{e}$ & $\begin{array}{l}\text { "to swear at } \\
\text { someone" }\end{array}$ & MH-rising & $\mathrm{MH}$ & /MH/ \\
\hline$\| \bar{a} \hat{o}$ & “wing” & ML-falling & ML & /ML/ \\
\hline
\end{tabular}

Table 1: Tonological analysis of the six contrastive Tsua melodies

With respect to the two monotonal melodies High-level and Mid-double-rise, there are tokens in which the Tsua speakers produce a phonetically level to slightly falling F0 during the second mora. These tokens do not conform to a particular pattern. This characteristic of the two Tsua monotonal melodies is similar to what Brugman (2009) reports for Khoekhoe for four monotonal melodies. She writes that while the pitch targets are reached during the first mora, the second mora has a phonetic fall indicating an unspecified root-final tone in her analysis.

The same phonetic characteristic is reported in Morén and Zsiga (2006) and Zsiga and Nitisaroj (2007) for Thai. The authors state: "During moras with no phonological tone, pitch falls gradually to or within the mid-range" (Zsiga and Nitisaroj 2007:347). Given the phonetic properties of the two Tsua monotonal melodies in addition to what has been found in Khoekhoe and Thai, it is plausible that $/ \mathrm{H} /$ and $/ \mathrm{M} /$ spreading to the second mora is optional in Tsua, leaving the second mora underspecified for tone in some tokens.

Autosegmental representations for Tsua tone melodies are proposed in (2) below. The parentheses for the High-level and Mid-double-rise melodies indicate optionality to account for the tokens where the consultants produce their respective pitches as phonetically level or slightly falling with no specific target during the second mora. 
(2) Tsua lexical tone representations

a. Bimoraic sequence in citation forms

\section{High-level HM-falling HL-falling Mid-double-rise MH-rising ML-falling}

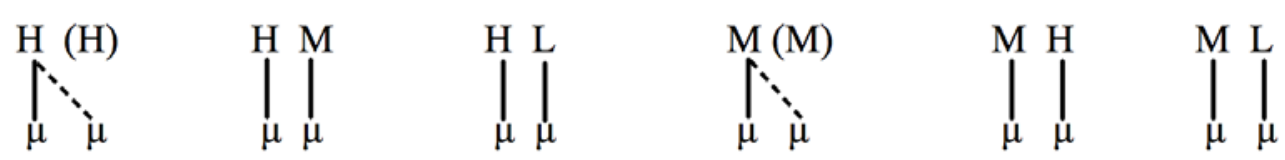

\subsection{High Tone Lowering}

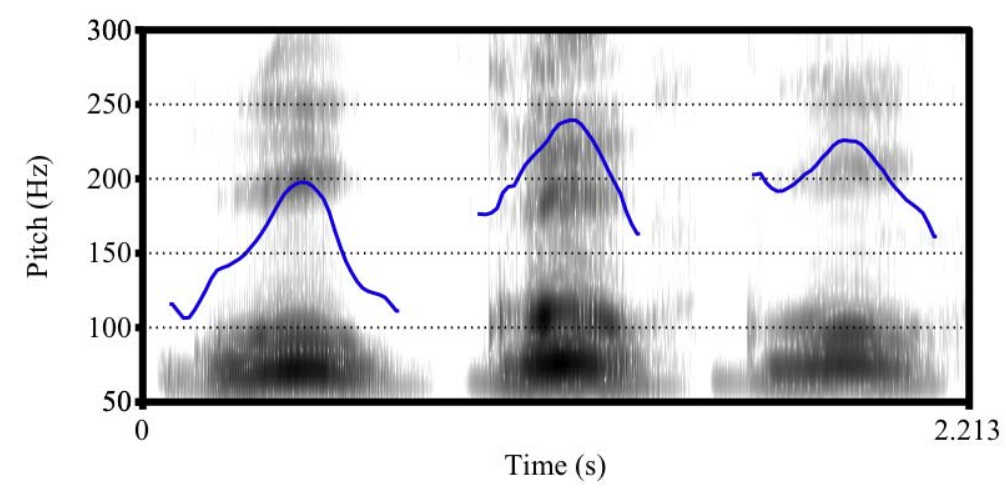

Figure 7: F0 traces with spectrograms of the DH-L noun [goo] "aardvark" spoken in citation form by speakers $S, B$ and $M$ displayed from left to right

There are two melodies with root-initial depressed High tones: DH-L and DH-M. A DH-H melody is not found in the current data set. Henceforth, the DH-L and DH-M tonal transcriptions are marked with an ' $\mathrm{x}$ ' symbol $\left[{ }_{*}\right.$ ] below the vowel with the depressed $\mathrm{H}$ tone, i.e. [ạaà] is DH-L and [ạa â] is DH-M. Typical DH-L contours are seen in Figure 7 for the three Tsua consultants. These examples are productions of the noun [góò] "aardvark”. For speakers $\mathrm{S}$ and $\mathrm{B}$, there is an $\mathrm{F} 0$ decrease of $80 \mathrm{~Hz}$ or more at the onset of the $\mathrm{H}$ tone realization compared to a typical non-depressed $\mathrm{H}$ tone. Speaker $\mathrm{M}$ has a more modest $\mathrm{F} 0$ decrease of about $40 \mathrm{~Hz}$ in this example at her pitch contour onset. The contours rise to their respective $\mathrm{H}$ tone targets. After the F0 peaks, they fall sharply to the L tone targets. 


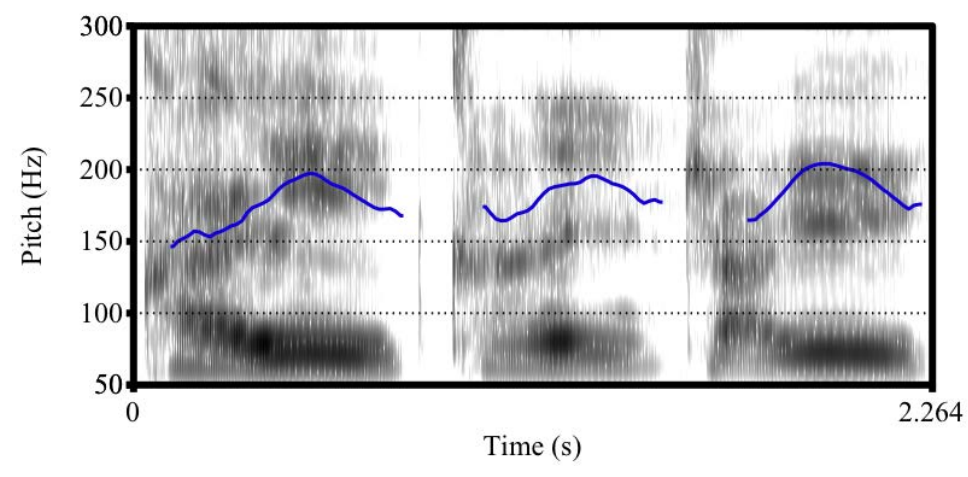

Figure 8: F0 traces with spectrograms of the DH-M verb: [ $k^{\text {hae] }}$ "to stab" spoken in citation form by speakers $S, B$ and $M$ displayed from left to right

DH-M F0 tracings are seen in Figure 8. In general, the DH-M contour has an F0 decrease in the realization of the first part of the initial tone of about $40-50 \mathrm{~Hz}$ compared to the initial tone of the non-depressed HM-falling tonal melody. F0 rises to the $\mathrm{H}$ tone target before it falls to the $\mathrm{M}$ tone target. Moreover, DH has a lower F0 compared to $\mathrm{M}$. There are two characteristics that distinguish DH-L from DH-M: (a) the DH-L F0 onset has a lower Hertz value compared to DH$\mathrm{M}$ for some tokens and (b) the F0 offset value is higher for DH-M as opposed to DH-L, with the F0 offsets being typical for Mid and Low tones.

Figure 9 shows superimposed F0 traces of HM [\|áē] "to chew” with DH-M [gláx̄] "thorn".

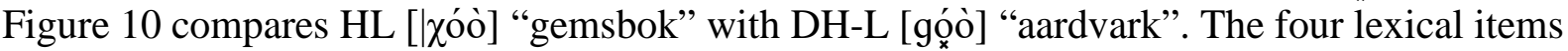
are produced by speaker S. The figures are a striking depiction of depressed versus nondepressed contours, thus illustrating how crucial data visualization is for the analysis of Tsua tonal melodies. The F0 lowering for the depressed melodies is apparent at their respective onsets. The curves converge and fall to their F0 offsets. The fact that the curves converge from their midpoints until the F0 offsets confirms the root-final $\mathrm{M}$ and $\mathrm{L}$ tone interpretations, respectively. It is noteworthy that the F0 lowering is more pronounced for the DH-L melody $(100 \mathrm{~Hz})$ than the DH-M melody $(50 \mathrm{~Hz})$ for these particular tokens.

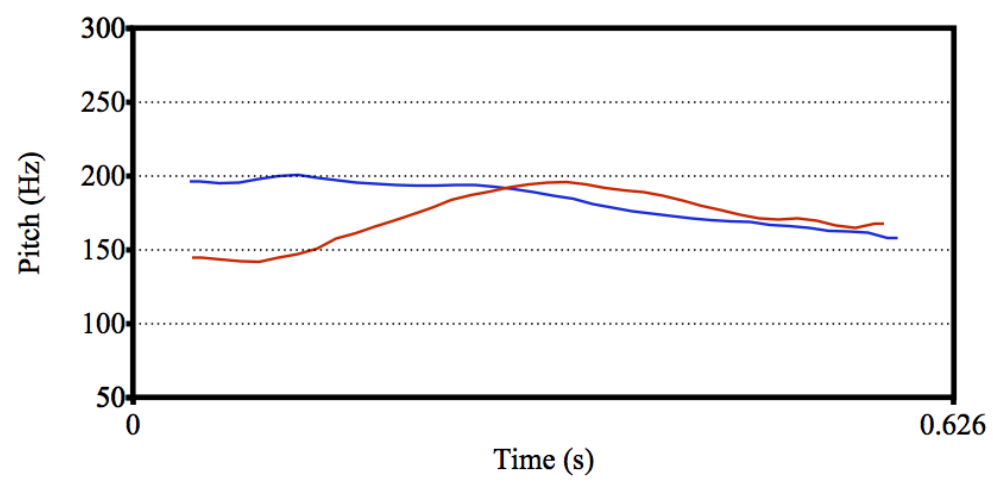

Figure 9: F0 traces of HM [\|áē] “to chew” (blue) and DH-M [g\|ấ̄̄] “thorn” (red) to illustrate $\mathrm{H}$ tone depression in Tsua as produced by speaker S. Fo lowering is realized at the start of pitch onset. The curves converge and fall to similar F0 offsets. 


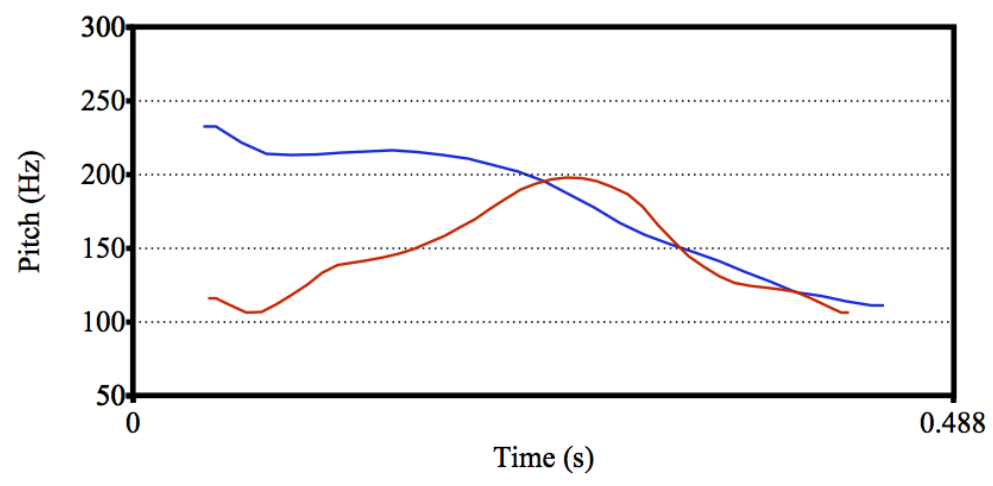

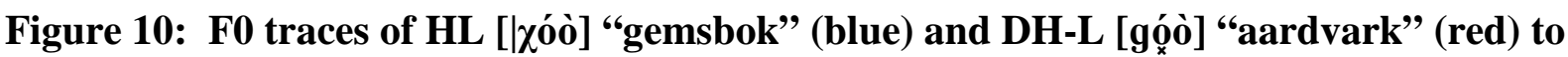
illustrate $\mathrm{H}$ tone depression in Tsua as produced by speaker S. FO lowering is realized at the start of pitch onset. The curves converge and fall to similar F0 offsets.

\section{High Tone Raising}

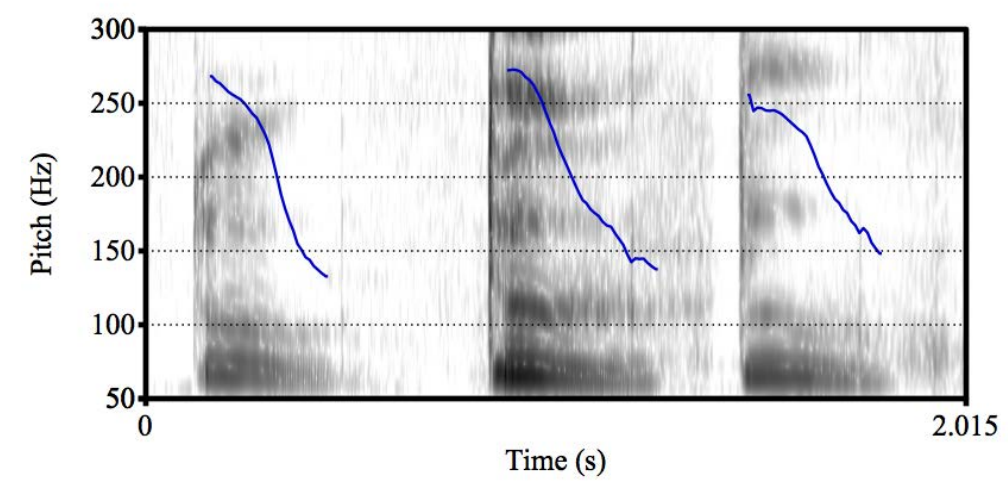

Figure 11: F0 traces with spectrograms of the SH-L noun [tüù "to collect and remove ash” spoken in citation form by speakers $S, B$ and $M$ displayed from left to right.

HTR has been observed affecting HH, HM and HL melodies. A typical HL-falling melody previously shown in Figure 3 had F0 onsets of approximately 200, 250 and $225 \mathrm{~Hz}$ for speakers $\mathrm{S}, \mathrm{B}$ and $\mathrm{M}$, respectively. In the case of [tüù] "to collect and remove ash" with two successive high vowels [u], the F0 onsets are approximately 260, 275 and $255 \mathrm{~Hz}$ for S, B and M, respectively. The largest F0 onset difference is observed with speaker S at $60 \mathrm{~Hz}$. F0 falls quickly to the respective F0 offsets of 125,130 and $150 \mathrm{~Hz}$ as seen in Figure 11. These F0 offset values are similar to typical F0 offsets for the HL-falling tokens in the data set. It appears that even though there are two successive high vowels [u] in [tüù], it is the $\mathrm{H}$ tone that is raised to $\mathrm{SH}$ while the root-final $\mathrm{L}$ tone remains unaffected. There is no evidence to suggest that $\mathrm{M}$ tones are raised when docked to $[\mathrm{i}, \mathrm{u}]$ in the current data set. Moreover, there are examples in the data set where an $\mathrm{H}$ tone docked to a high vowel follows a depressor. For instance, [q⿳⺈冂䒑⿱r. $\bar{u}$ ] "a cloud of dust" in which the speakers produce a typical DH-M melody. HTR is blocked when a depressor consonant precedes. It should be noted that the three Tsua consultants produced 
$[\mathrm{SH}]$ optionally; they would at times produce $[\mathrm{SH}]$ and other times $[\mathrm{H}]$. There does not appear to be any difference in interpretation. Therefore, HTR would need to be optional and is not just a phonetic effect.

\section{Discussion}

Figures 7-10 demonstrate that the F0 target at the start of the depressed $\mathrm{H}$ contours is consistent with a Low tone interpretation, in part because it is distinct from and below a root-initial Mid tone target. Subsequently, the curves rise to their respective High tone targets followed by a fall to the root-final tones. The curves do not show evidence of High tone deletion. In addition, the statistical analyses in Mathes (2015) demonstrate that depression caused by voiced and aspirated obstruents is phonetically identical. Nevertheless, the realization of a depressed $\mathrm{H}$ tone is subject to variability depending on the following tone (Figures 9 and 10). We would need to assume that there is some phonetic leeway in terms of Tsua HTL.

There are a number of cases in which HTL does not occur following voiced obstruents. For instance, the HM [g\|óē] "moon” and the HL [gllào] "to age; old" have root-initial voiced lateral clicks. If HTL were a purely phonetic effect, we would expect the F0 trajectories to be consistently influenced in a similar fashion by a preceding depressor consonant such as a voiced click (see Figure 9). This is not the case for the exceptions. In all of the cases, comparative evidence suggests that these voiced obstruents were historically nasal (Mathes 2015). Nasal consonants are not depressors in Tsua. These exceptions provide evidence that Tsua F0 lowering involves a phonological process.

The structure of $[\mathrm{DH}]$ could be analysed as resulting from a Low tone insertion rule. Under this view, the anatomy of [DH] would simply be [LH]. Thus, DH-L is [LH-L] and DH-M is [LH$\mathrm{M}]$. The Tsua HTL rule is given in (3).

(3) Tsua HTL rule with the [+slack] feature

$$
\emptyset \rightarrow \mathrm{L} /[\text {-sonorant, +slack] _ } \mathrm{H}[-\mathrm{H}] \#
$$

In (3), a Low tone is inserted in the environment following [-sonorant], [+slack] and when followed by a sequence of a High tone plus a non-high tone (i.e. $\mathrm{M}$ or $\mathrm{L}$ ). The rule in (3) appeals to the unifying feature [+slack] as the source of HTL in Tsua. The three depressor types, i.e. voiced obstruents, aspirated obstruents and the glottal fricative /h/, would have had [+slack] as the feature responsible for F0 lowering.

The effect of prevocalic voiced stops on F0 has been studied for quite some time (e.g., House and Fairbanks 1953; Lehiste and Peterson 1961; Löfqvist 1975; among others). The data from these and other studies make clear that the F0 of a following vowel is higher after voiceless than after voiced stops, and it does not vary as a function of place of articulation (Hombert et al. 1979:39). The common cross-linguistic pattern of F0 lowering by prevocalic voiced stops holds for tonal as well as non-tonal languages. The studies in Hombert (1978) confirm this pattern by presenting the F0 perturbation time course after voiced stops in Yoruba and American English. In sum, the postvocalic F0 lowering caused by voiced obstruents compared to voiceless obstruents has been reported in numerous phonetic studies and can be attributed to 
slackening of the vocal folds (Halle and Stevens 1971; Kingston and Diehl 1994). The slackening gesture is the articulatory correlate of the [+slack] feature (Halle and Stevens 1971).

The effect of aspirated stops is less consistent with respect to F0 perturbation trends crosslinguistically. An F0 lowering effect by aspirated obstruents occurs in tone languages spoken in Africa and Asia. However, there are languages in which a higher F0 has been reported after aspirated obstruents compared to unaspirated obstruents. For instance, data from Danish (Jeel 1975), Korean (Han and Weitzman 1970), Cantonese (Zee 1980), Thai (Gandour 1974) and Japanese (Ewan 1976) show that an aspirated stop gives rise to a higher F0 at the onset of the following vowel (as cited in Xu and Xu 2003:165). It appears that there is a dichotomy between F0 lowering and raising after aspirated obstruents across languages.

Appealing to the [+slack] feature as the unifying source of Tsua's synchronic tonal depression is complicated by classificatory systems that consider voiceless, aspirated obstruents as [-slack] (e.g. Halle and Stevens 1971:51). Nonetheless, Chen (2011:622) states: "To the extent that aspirated stops do introduce different perturbation effects as compared to their voiceless unaspirated counterparts, the cross-linguistic variability suggests that speakers may use different strategies to produce aspirated stops in different languages which lead to different perturbation effects." Citing the vocalis muscle effects described in Hoole (2006), Chen continues:

Although vocal fold activity is a very complex phenomenon and much still remains to be learned, we may hypothesize that languages can differ in the strength of the vocalis muscle effects...It is possible that in Shanghai Chinese at the release of an aspirated stop, such an effect is either weak or not as effective as those after a voiceless unaspirated stop since the glottis opening after an aspirated stop is much greater. This in turn may lead to relative slackness of the vocal folds at the onset of the vowel after an aspirated onset, resulting in a certain amount of extended glottal opening and gradual onset of voicing. Consequently, there is a breathy transition between the aspiration and the vowel voicing with weak glottal buzz, manifested in higher $\mathrm{H} 1-\mathrm{H} 2$ and $\mathrm{fO}$ lowering, as compared to voiceless unaspirated stops. In other words, not only the timing of laryngeal adjustments relative to supraglottal gestures (manifested as the VOT values) are important to differentiate stop contrasts, the state of the glottis constriction (e.g., spread vs. constricted and/or stiff vs. slack) can also play a role even in cases where VOT seems to be a sufficient cue for phonological distinctions (Chen 2011:622).

If Chen's hypothesis is on the right track, then vocal fold slackness may have caused the F0 lowering following aspirated obstruents in Tsua, assuming that aspiration is articulated in a similar fashion as described above for Shanghai Chinese.

The voiceless glottal fricative $/ \mathrm{h} /$ is an additional complication to the [+slack] possibility, because it is classified with the feature [-slack] (Halle and Stevens 1971:51). There are two pieces of evidence to consider in this case. First, we may look at the related language Shua. Westphal's handwritten field notes (n.d.) on Shua verb tense and pronouns have the voiced glottal fricative [h] in the transcriptions. For example, [hĩi] "to work" and [hife] "you (fem.)". 
The handwritten transcription of [ $\mathrm{h}$ ] does not seem to be Westphal's idiosyncratic way of writing ' $h$ ' in general, because he clearly transcribes "to stab” as [khae] and "person” as [khwe].

Second, we may consider evidence from Ikalanga, the neighbouring Bantu language that has had extensive contact with Tsua, which could have been a source of historical influence on Tsua phonology (Chebanne 2014). Ikalanga has the voiced glottal fricative / $\mathrm{h} /$ as a depressor in its inventory (Mathangwane 1999:175). The voiced glottal fricative / $\mathrm{h} /$ is categorized as [+slack] by Halle and Stevens, which would explain its F0 lowering effect on a following tone. We speculate that Tsua's voiceless glottal fricative /h/ may have been historically voiced as a result of contact with Ikalanga and the F0 lowering became phonologised. Under this view, /h/ became devoiced in Tsua but remained voiced in the Shua dialects at the time of Westphal's field research. It may be that Tsua's tone system was influenced via contact with neighbouring languages such as Ikalanga. The Tsua tonal space could be undergoing contact-induced reorganization. It is a possibility that necessitates further study.

HTR may be the consequence of the Intrinsic F0 (IF0) effect from Tsua's high vowels [i, u]. Intrinsic F0 is the tendency for high vowels to have a higher fundamental frequency than low vowels. This phonetic feature has been found in every language that has been examined for it (Whalen and Levitt 1995 and references cited therein). Some proposals have suggested that IF0 is a deliberate process used to enhance vowel category differences (e.g. Kingston 1993). Others have suggested that IF0 is the result of vowel articulation (Shadle 1985). In a study of 31 languages from 11 major language families, Whalen and Levitt (1995) found means of 177.4 $\mathrm{Hz}$ for [u], $174.9 \mathrm{~Hz}$ for [i] and $160.9 \mathrm{~Hz}$ for [a] across all languages, a $15.3 \mathrm{~Hz}$ IF0 difference between high and low vowels.

The F0 traces in Figure 11 show an /H/ tone onset differential for [u] of $60 \mathrm{~Hz}, 25 \mathrm{~Hz}$ and 30 $\mathrm{Hz}$ for speakers $\mathrm{S}, \mathrm{B}$ and $\mathrm{M}$, respectively, when compared to the typical onset when the $\mathrm{H}$ tone is docked to a non-high vowel. The magnitude of the difference suggests a synchronic phonological process. More importantly, as stated earlier, the three Tsua consultants produced $[\mathrm{SH}]$ optionally; they would at times produce [SH] and other times $[\mathrm{H}]$. There does not appear to be any difference in interpretation. If this were a purely phonetic process, we would expect F0 raising to be consistent. Thus, HTR would need to be optional. An autosegmental derivation of the process is given in (4).
tuu
UR
HL
$\begin{array}{ll}\text { tuu } & \text { Tone Assignment } \\ \text { I I } & \end{array}$
$\prod_{\text {SH L }}^{\text {tuu HTR (optional) }}$

/H/ surfaces as $[\mathrm{SH}]$ when docked to [i] or [u]. Recall that for HTL, a DH-H melody is not found in the current data set, an absence due to a co-occurrence restriction in which depressors 
do not occur with $/ \mathrm{H} /$. On the other hand, for HTR, there are examples of [SH-SH] sequences derived from /H/, for example, [pídi'] "goat". HTR would be ordered before tone spreading in these cases. Moreover, the fact that Mid and Low tones do not undergo consistent raising is in line with the findings that the IF0 effect disappears in the lower part of the F0 range for some tone languages (Whalen and Levitt 1995). In sum, it is plausible that HTL and HTR may have had origins that were phonetic in nature, being phonologised at a later point in time.

\section{Conclusions}

HTL and HTR help explain the complex F0 trajectories observed in Tsua's lexical tone system. In terms of HTL, a Low tone insertion rule plausibly accounts for the observed F0 curves, potentially being the historical effect of the [+slack] feature. The IF0 effect on tones docked to high vowels may have been the source for HTR. This paper contributes to Khoisan phonetic and phonological typology, and further confirms the linguistic processes discussed in Chebanne (2014). Much still needs to be done to fully understand phonetically-driven language change, especially in contact situations.

\section{References}

Abramson, A.S. 1975. The tones of central Thai: some perceptual experiments. In J.G. Harris and J. Chamberlain (eds.). Studies in Thai Linguistics. Bangkok: Central Institute of English Language. pp. 1-16.

Abramson, A.S. 1978. Static and dynamic acoustic cues in distinctive tones. Language and Speech 21: 319-325.

Bradshaw, M.M. 1999. A crosslinguistic study of consonant-tone interaction. Ph.D. Dissertation, Ohio State University.

Brugman, J.C. 2009. Segments, tones and distribution in Khoekhoe prosody. Ph.D. Dissertation, Cornell University.

Chebanne, A.M. 2014. What have Eastern Kalahari Khoe languages lost linguistically? Stellenbosch Papers in Linguistics Plus 44: 1-21.

Chebanne, A.M., and C. Collins. 2014. Kua lexicon. Unpublished field notes. University of Botswana and New York University.

Chen, Y. 2011. How does phonology guide phonetics in segment-f0 interaction? Journal of Phonetics 39: 612-625.

Elderkin, E.D. 1988. Patterns of sound in Northern Khoisan. African Languages and Cultures 1(2): 123-148.

Ewan, W.G. 1976. Laryngeal Behavior in Speech. Ph.D. dissertation, University of California, Berkeley.

Gandour, J. 1974. Consonant types and tone in Siamese. Journal of Phonetics 2: 337-350. 
Güldemann, T. 2006. Changing profile when encroaching on hunter-gatherer territory: Towards the history of the Khoe-Kwadi family in southern Africa. Historical Linguistics and Huntergatherer Populations in Global Perspective. Leipzig: Max Planck Institute for Evolutionary Anthropology.

Güldemann, T., and R. Vossen. 2000. Khoisan. In B. Heine and D. Nurse (eds.). African languages: An introduction. Cambridge, United Kingdom: Cambridge University Press. pp. 99122.

Haacke, W.H.G. 1999. The Tonology of Khoekhoe (Nama/Damara). Windhoek (Quellen zur Khoisan-Forschung 16). Köln: Rüdiger Köppe.

Haacke, W.H.G. 2008. Tonogenesis in flagrante: Tonal depression in Khoekhoegowab, Haillom, $\neq$ Akhoe and Naro. In S. Ermisch (ed.). Proceedings of the 2nd International Symposium on Khoisan Languages and Linguistics. Riezlern/Kleinwalsertal: Rüdiger Köppe Verlag. pp. 153-184.

Hagman, R.S. 1977. Nama Hottentot grammar. Bloomington: Indiana University.

Halle, M., and K.N. Stevens. 1971. A note on laryngeal features. MIT Research Laboratory of Electronics Quarterly Progress Report 101: 198-213.

Han, M.S., and R.S. Weitzman. 1970. Acoustic features of Korean /P, T, K/, /p, t, k/ and /ph, th, kh/. Phonetica 22: 112-128.

Hombert, J.-M. 1978. Consonant Types, Vowel Quality, and Tone. In V.A. Fromkin (ed.). Tone: A Linguistic Survey. New York, NY: Academic Press, Inc. pp. 77-111.

Hombert, J.-M., J.J. Ohala, and W.G. Ewan. 1979. Phonetic explanations for the development of tones. Language 55: 37-58.

Hoole, P. 2006. Experimental studies of laryngeal articulation. Germany: Habilitationschrift, University of Munich.

House, A.S., and G. Fairbanks. 1953. The influence of consonant environment upon the secondary acoustical characteristics of vowels. Journal of the Acoustical Society of America 25: 105-113.

Jeel, V. 1975. An investigation of the fundamental frequency of vowels after various Danish consonants, in particular stop consonants. Annual Report of the Institute of Phonetics, University of Copenhagen: 191-211.

Kingston, J. 1993. The phonetics and phonology of perceptually motivated articulatory covariation. Language and Speech 35: 99-113.

Kingston, J., and R.L. Diehl. 1994. Phonetic knowledge. Language 70: 419-454.

Laver, J. 1994. Principles of phonetics. Cambridge University Press. 
Lehiste, I., and G. Peterson. 1961. Some basic considerations in the analysis of intonation. Journal of the Acoustical Society of America 33: 419-425.

Löfqvist, A. 1975. Intrinsic and extrinsic F0 variations in Swedish tonal accents. Phonetica 3: 226-247.

Mathangwane, J.T. 1999. Ikalanga Phonetics and Phonology: A Synchronic and Diachronic Study. Stanford, CA: CSLI Publications.

Mathes, T.K. 2015. Consonant-tone interaction in the Khoisan language Tsua. Ph.D. Dissertation, New York University.

Mathes, T.K. 2016. The segmental inventory and status of click replacement in Tsua. In S. Shah and M. Brenzinger (eds.). Proceedings of the $5^{\text {th }}$ International Symposium on Khoisan Languages and Linguistics. Riezlern/Kleinwalsertal: Rüdiger Köppe Verlag. pp. 221-242.

Morén, B., and E. Zsiga. 2006. The lexical and post-lexical phonology of Thai tones. Natural Language \& Linguistic Theory 24: 113-178.

Nakagawa, H. 2006. Aspects of the phonetic and phonological structure of the G|ui language. Ph.D. Dissertation, University of the Witwatersrand, Johannesburg.

Nakagawa, H. 2009. A preliminary phonetic investigation of the lexical tones of G|ui. Working Papers in Corpus-based Linguistics and Language Education 3: 45-52.

Shadle, C.H. 1985. Intrinsic fundamental frequency of vowels in sentence context. Journal of the Acoustical Society of America 78: 1562-1567.

Tang, K.E. 2008. The phonology and phonetics of consonant-tone interaction. Ph.D. Dissertation, UCLA.

Vossen, R. (ed.) 2013. The Khoesan Languages. London and New York: Routledge.

Westphal, E.O.J. n.d. Shua. (BC 1143 (C8), E O J Westphal Papers). Unpublished notes housed at the Rare Documents and Manuscripts Department, University of Cape Town.

Whalen, D.H., and A.G. Levitt. 1995. The universality of intrinsic $\mathrm{F}_{0}$ of vowels. Journal of Phonetics 23: 349-366.

Xu, C.X., and Y. Xu. 2003. Effects of consonant aspiration on Mandarin tones. Journal of the International Phonetic Association 33(2): 165-181.

Zee, E. 1980. The effect of aspiration on the F0 of the following vowel in Cantonese. UCLA Working Papers in Phonetics 49: 90-97.

Zsiga, E., and R. Nitisaroj. 2007. Tone features, tone perception, and peak alignment in Thai. Language and Speech 50(3): 343-383. 